This item is the archived peer-reviewed author-version of:

Reinforcement learning in child molesters

\title{
Reference:
}

Dilliën Tineke, Goethals Kris, Sabbe Bernard, Brazil Inte.- Reinforcement learning in child molesters

Criminal behaviour and mental health - ISSN 0957-9664 - 29:1(2019), p. 31-42

Full text (Publisher's DOI): https://doi.org/10.1002/CBM.2097

To cite this reference: https://hdl.handle.net/10067/1551860151162165141 


\section{Reinforcement Learning in Child Molesters}

\section{Tineke Dillien $^{1,2}$, Kris Goethals ${ }^{1,2}$, Bernard Sabbe ${ }^{1,3}$, Inti A. Brazil ${ }^{1,4,5,6}$}

${ }^{1}$ Collaborative Antwerp Psychiatric Research Institute, University of Antwerp, Belgium

${ }^{2}$ University Forensic Centre, Antwerp University Hospital, Belgium

${ }^{3}$ University Psychiatric Centre Duffel, Antwerp University Hospital, Belgium

${ }^{4}$ Donders Institute for Brain, Cognition and Behaviour, Radboud University, Nijmegen, The

Netherlands

${ }^{5}$ Forensic Psychiatric Centre Pompestichting, Nijmegen, The Netherlands

${ }^{6}$ Centre for Advances in Behavioural Sciences, Coventry University, England

Conflicts of Interest: None

Author Note: Tineke Dillien was supported by a Dehousse mandate of the University of Antwerp. Inti A. Brazil was supported by a VENI grant (451-15-014) awarded by the Netherlands Organization for Scientific Research (NWO).

Correspondence to Tineke Dillien, University of Antwerp, Faculty of Medicine and Health Sciences Campus Drie Eiken D.R.320, Universiteitsplein 1, 2610 Wilrijk, Belgium. Email: tineke.dillien@uantwerpen.be

Keywords: Adaptive behaviour; Child molesters; Reinforcement learning; Reversal learning; Forensic Psychiatry. 


\begin{abstract}
Background: Child molesters form a heterogeneous group, but one generally shared characteristic is maladaptive, rigid behaviour. Impairments in reinforcement learning may explain these maladaptive tendencies, but this has not been systematically investigated. Further, it is not known if such impairments vary with subtype of child molesters.

Aims: To investigate the presence of impairments in reinforcement learning among child molesters and to test for differences in patterns of impairment with subtype.

Methods: A group of 59 child molesters was recruited from several prisons in a two stage screening process, the first using records and the second interview; a comparison group of 33 offenders who had never committed a sex offence and who denied paedophile ideation was similarly recruited; 36 non-offender comparison men were recruited by social media and word of mouth. Each was asked to perform a probabilistic reversal learning task, in which stimulusoutcome contingencies had to be learned.
\end{abstract}

Results: Child molesters, as a group, made significantly more errors on the probabilistic reversal learning task than the non-offenders; the offender controls and the non-offenders gained similar scores, although findings may have been counfounded by older age in the child molester group. Non-paedophilic child molesters had significantly worse scores than paedophilic child molesters.

Conclusions: Child molesters, especially those not diagnosed with paedophilia, have deficits during both the acquisition and reversal of contingencies, suggesting reinforcement learning deficits which may undermine their capacity to benefit maximally from therapy without preliminary work to repair those deficits, possibly in conjunction with extending the offender programmes. Testing before programme entry would enable accurate targeting of scarce resources in this respect. 


\section{Introduction}

In order to function optimally in the world, we learn which choices to make and how to act based on the value of the outcomes, which act as reinforcement (Behrens, Hunt, Woolrich, \& Rushworth, 2008). Reinforcement learning helps us engage in the exploitation of choices that lead to positive outcomes, while those that lead to unfavourable outcomes are avoided. In addition to acquiring contingencies (i.e., acquisition learning), we also need to adjust our behaviour accordingly when contingencies change and previously rewarded choices and behaviours become inappropriate (i.e., reversal learning; Cools, Clark, Owen, \& Robbins, 2002). Reinforement learning has a strong neurobiological basis (e.g., Behrens et al., 2008; Cools et al., 2002), and disturbances in the mechanisms subserving it have been linked to many psychiatric conditions typified by maladaptive behaviour (e.g., Chen, Takahashi, Nakagawa, Inoue, \& Kusumi, 2015; Waltz \& Gold, 2007).

Persistent antisocial behaviour, seen in violent offenders with psychopathy has also been linked to impaired reinforcement learning. Studies have consistently demonstrated that they show selective impairments in response reversal (e.g., Budhani, Richell, \& Blair, 2006; Mitchell, Colledge, Leonard, \& Blair, 2002; Mitchell et al., 2006). From a clinical perspective, this finding parallels the commonly seen inclination to keep exhibiting antisocial behaviour despite having faced criminal sanctions (Kiehl \& Hoffman, 2011). More recent work, however, has pointed out that reversal learning deficits are not only found in offenders with high psychopathy scores, but also in offenders with a subthreshold score on the PCL-R (Dargis, Wolf, \& Koenigs, 2017; Mitchell et al., 2006) and in offenders with a diagnosis of antisocial personality disorder, but without high psychopathy checklist scores (De Brito, Viding, Kumari, Blackwood, \& Hodgins, 2013).

Despite indications that reversal learning deficits may occur among offenders with low psychopathy scores, this line of research has yet to be extended systematically to other 
offenders who show persistent antisocial behaviours, such as child molesters. Although their overall sexual reoffending rate is low, they form a heterogenous group and some subgroups pose a high risk, such as offenders against boy victims who have the highest sexual recidivism rates of all hands-on sexual offenders (Harris \& Hanson, 2004), up to 64\% over 15 years (Vess \& Skelton, 2010). These findings suggest that at least some subtypes of child molester show difficulties in adapting dysfunctional behaviours, despite the prospect of reincarceration. It is still unknown, however, whether this behavioural rigidity is related to reinforcement learning deficits. Only one study so far has examined this form of learning in a mixed group of sex offenders, including those targeting children (Leue, Brocke, \& Hoyer, 2008). In this study, 51 healthy controls, 50 paraphilic and 48 non-paraphilic sex offenders performed a computerised choice task and were instructed to earn as many points as possible by pressing one of two buttons. After the first phase in which both buttons were rewarded, one of the two buttons was no longer rewarded, which required subjects to adapt their behaviour. The findings showed that non-paraphilic sex offenders were less able to adapt to changing contingencies, relative to the controls and the paraphilic sex offenders, indicating reversal learning impairment among the non-paraphilic offenders. This study does not, however, provide sufficient insights into the nature of the impairments found. Since acquisition learning was not assessed, this study was not able to elucidate whether the maladaptive tendencies seen in non-paraphilic sex offenders reflect a specific impairment in reversal learning or a more general reinforcement learning deficit. The study samples of sex offenders, moreover, were heterogeneous, with, variously, adult or child victims. Since Joyal, Beaulieu-Plante, and de Chantérac (2014) demonstrated that child molesters and rapists have different cognitive profiles, they may not necessarily show similar reinforcement learning profiles. Furthermore, Joyal et al. (2014) showed a high degree of within-group variance in the cognitive functioning of child molesters, and argued that subgroups (e.g. paedophilic/non-paedophilic) should be 
dealt with separately in cognitive examinations. Paedophilic and non-paedophilic child molesters are distinguished by clinical presentation, offence characteristics, and underlying motivations for sexually abusing children.The paedophilic subgroup is driven by deviant sexual preferences, while the non-paedophilic child molesters are sexually attracted to adults but abuse children for a variety of other reasons, including emotion regulation problems, antisocial inclinations, poor impulse control, the need for power and control (Eastvold, Suchy, \& Strassberg, 2011; Suchy, Whittaker, Strassberg, \& Eastvold, 2009).

Our main aim was to investigate for the first time whether reinforcement learning is impaired in child molesters and, if so, which aspects of it are affected. Our first hypothesis was that child molesters would show reinforcement learning impairments - relative to nonoffenders and offenders without sexual offending histories - at least in reversal learning. Our additional aim was to explore differences between child molesters in this respect, with the hypothesis that non-paedophilic child molesters would show more impaired reinforcement learning than paedophilic child molesters.

\section{Method}

\section{Ethics}

This experiment was part of a larger study about the cognitive functions of child molesters, which was approved by the medical ethics committee of the University of Antwerp. All participants signed an informed consent form and received $10 €$ for participating.

\section{Design, Participants and Procedure}

A cross sectional, group comparison design was chosen. All offenders were recruited from eight Flemish prisons between February 2016 and July 2017. The core criterion for inclusion in the child molester group was at least one conviction for sexually abusing a child aged 13 years or younger. The criterion for offender controls was having had at least one 
conviction for a violent offence, but no history of sexual offending or self-reported paedophilic sexual interest. The non-offenders were recruited from the community by social media and word of mouth and were screened using the same procedure as for the offenders. Core criteria for inclusion were male sex and similar age and IQ group to the offender particpants, and no evidence of criminal convictions or self-reported paedophilic sexual interest

In order to identify eligible candidates, prison psychologists used files to pre-screen prisoners (all male) for age (18-65 years), IQ (full scale IQ>79), no (current or lifetime) serious psychiatric nor neurological disorder, and no substance abuse within the last year. Based on this pre-screening, 138 offenders were invited to attend information sessions in which the study was explained. For those who were willing to participate, fit with the inclusion criteria was checked during a separate screening session. In this session, a semistructured interview designed for this study was administered. This interview covered demographic factors, sexual behaviour, offending behaviour, and criminal history, and was used in conjunction with the Structured Clinical Interview for DSM-IV Axis I (Van Groenestijn, Akkerhuis, Kupka, Schneider, \& Nolen, 1999) and Axis II Personality Disorders (Weertman, Arntz, \& Kerkhofs, 2000) to rule out serious psychiatric disorder. When possible, the self-report information regarding offending was compared to prison records. The Dutch version of the National Adult Reading Test (NLV; Schmand, Bakker, Saan, \& Louman, 1991) was administered to estimate the level of intelligence. The participation rate was $71 \%$ and $61 \%$ for the child molesters and offender controls, respectively.

\section{Assessment tools}

The Self-Report Psychopathy Short-Form (SRP-SF; Paulhus, Delroy, Neumann, \& Hare, 2016) was used to assess psychopathy. This measure yields 2 factor scores (i.e., interpersonalaffective and impulsive-antisocial) and a total psychopathy score (see Appendix A). 
The Screening Scale for Pedophilic Interest (Seto \& Lalumière, 2001) and/or the viewing reaction time paradigm, taken from the Explicit and Implicit Sexual Interest Profile (Schmidt, Gykiere, Vanhoeck, Mann, \& Banse, 2013) were used to supplement self-reported sexual preferences of child molesters who denied being sexually attracted to children. The presence of paedophilia among the child molesters was determined according to the DSM-IV-TR criteria (American Psychiatric Association, 2000), using information collected during the semistructured interview. .

\section{The reinforcement learning task}

A computerised probabilistic reversal learning task developed by Budhani et al. (2006) was used. In each of the 270 task trials, a pair of animals was presented to a participant who had to learn to choose the correct animal. After choosing one of the animals, feedback was presented to him and rewards or punishments (fake money given or withdrawn) were given. Participants were instructed to earn as much money as possible. In total, six pairs of animals were presented throughout the task. Four of these pairs had a 100-0 contingency, with the correct option always being rewarded and the incorrect option always being punished. The remaining two pairs had an 80-20 (i.e., a probabilistic) reinforcement contingency. In these pairs, the correct option was rewarded in $80 \%$ and punished in $20 \%$ of the trials. The incorrect option, in turn, was rewarded in $20 \%$ and punished in $80 \%$ of the trials. Of the six animal pairs, two pairs were reversing and four pairs were non-reversing. While the rewardpunishment contingencies of the latter pairs remained constant throughout the task, the contingencies of the former pairs reversed (i.e., reversal phase) after having been constant for 40 trials (i.e., acquisition phase). Upon reversal, the correct option became the incorrect one and vice versa, requiring the subject to adapt his behaviour. One of the reversing and one of the non-reversing pairs had an 80-20 contingency. The other pairs had a 100-0 contingency 
(see also Appendix A). A learning criterion of eight consecutive correct responses per pair was maintained to indicate that learning had occurred (Budhani et al., 2006).

\section{Planned data analysis}

First, Fisher's exact tests were used to compare the proportion of child molesters (CM), offending controls (OC) and non-offenders (NO) who failed to reach the learning criterion. Next, the number of errors that were made prior to reaching the learning criterion was entered in a general linear model (GLM) with group (CM, OC, NO) as betweenparticipants factor, and phase (acquisition, reversal) and contingency (100-0, 80-20) as within-participant factors. For participants who did not reach the learning criterion in the acquisition phase, the reversal of learned contingencies could not be assessed. These participants were regarded as non-learners and excluded from further analysis (Budhani et al., 2006). When the learning criterion was not reached in the reversal phase, 'total errors made' rather than 'number of errors made prior to reaching the criterion' was used in the analysis (Budhani et al., 2006). Then, a second GLM was performed in a supplementary analysis to determine whether subgroups of child molesters differed in their reinforcement learning abilities. This model included subgroup (paedophilic CM, non-paedophilic CM) as betweenparticpants factor, with phase and contingency as within-participants factors. Finally, additional correlation analyses were conducted between the number of errors made and age, IQ, psychopathy scores, and length of incarceration to identify possible confounders in both models (see Appendix B).

\section{Results}

Two of the men convicted of a sexual offence against a child chose to discontinue the task, and the data of two control subjects had to be discarded due to technical malfunctions. 
Thus, data from 57 child molesters, 32 offender controls and 35 non-offenders were available for analysis.

\section{Failure Rate}

Ten child molesters and three offender controls failed to reach the learning criterion for one or both acquisition conditions and were excluded from further analysis. Of the remaining participants, twelve child molesters, two offender controls, and five non-offenders failed to reach the learning criterion for one of the reversal conditions (Table 1). When comparing the proportions of participants who failed the learning criterion, differences were only significant for child molesters versus non-offenders in the 80-20 acquisition (Fisher's exact test, $p=0.04$; Table 1 ).

Table 1 about here

\section{Error Rate}

After excluding the non-learners, 47 child molesters, 29 offender controls, and 35 nonoffenders remained. One-way analyses of variances (ANOVAs) were carried out to determine whether the groups differed on age, IQ, psychopathy scores, or length of incarceration. Table 2 summarises the characteristics of the three groups. The child molesters were significantly older $($ mean $(M)=46.74, \mathrm{SD}=10.99)$ than the comparison offenders $(\mathrm{M}=36.90, \mathrm{SD}=10.12$; $p<0.001)$ and the non-offenders $(\mathrm{M}=36.60, \mathrm{SD}=9.77 ; p<0.001)$; the comparison offenders and the non-offenders did not differ in age $(p=1.00)$. With respect to IQ, both the child molesters $(\mathrm{M}=102.07, \mathrm{SD}=10.95 ; p=0.00)$ and the comparison offenders $(\mathrm{M}=97.03, \mathrm{SD}=8.97$; $p<0.001)$ had significantly lower scores than the non-offenders $(\mathrm{M}=108.45, \mathrm{SD}=4.62)$, but there was no difference in this respect between the offender groups $(p=0.10)$. The groups also differed with respect to their psychopathy scores. The child molesters had significantly lower total SRP-SF scores $(M=62.04, S D=13.21)$ than the comparison offenders $(M=76.83$, 
$\mathrm{SD}=19.06, \mathrm{p}=0.00$ ), but significantly higher than the non-offenders (Mean=48.54, $\mathrm{SD}=14.24$; $p<0.001)$. Finally, the child molesters had spent significantly less time in prison at the time of testing $(\mathrm{M}=52.21, \mathrm{SD}=45.24)$ than the comparison offender $(\mathrm{M}=85.76, \mathrm{SD}=74.82 ; p=0.04)$.

Table 2 about here

The general linear model revealed a significant main effect for Group $[F(2,108)=4.21$, $p=0.02]$, which showed that the groups differed in the number of errors committed prior to reaching the learning criterion. Games-Howell post-hoc analyses showed that while the child molesters made significantly more errors $(\mathrm{M}=4.92, \mathrm{SE}=0.29)$ than the non-offenders $(\mathrm{M}=3.63, \mathrm{SE}=0.34 ; p=0.01$, see Figure 1$)$, they were not significantly different in this respect from the comparison offenders $(M=4.41, S E=0.37)$, whose scores, in turn, did not differ significantly from those of the non-offenders. There was also a significant main effect for Phase $[F(1,108)=88.37, p<0.001]$. Bonferroni adjusted pairwise comparisons showed that participants taken together made significantly more errors during the reversal (Mean=5.97, $\mathrm{SE}=0.29$ ) than during the acquisition phase (Mean=2.67, $\mathrm{SE}=0.23$ ). A significant effect for contingency $[F(1,108)=94.74, p<0.001]$ showed higher error rates for the 80-20 $($ Mean=6.00, $\mathrm{SE}=0.31)$ versus the 100-0 contingency $(\mathrm{Mean}=2.65, \mathrm{SE}=0.19)$. A significant Phase $\times$ Contingency interaction $[F(1,108)=35.73, p<0.001]$ indicated that the effect of contingency on the number of errors made was greater in the reversal than in the acquisition phase, however there were no significant Group $\times$ Phase $[F(2,108)=0.48, p=0.62]$ or Group $\times$ Phase $\times$ Contingency $[F(2,108)=0.61, p=0.55]$ interactions. Thus not only did all groups make more errors during the reversal phase, but also the PhasexContingency interaction was the same for all groups.

Figure 1 about here 


\section{Within-Group Analysis for the child molesters}

Subgroup-specific performance was compared between paedophilic $(n=17)$ and nonpaedophilic child molesters $(n=30)$. Table 3 summarises the characteristics of the two groups. The non-paedophilic child molesters, as a group, had a significantly lower IQ score $(\mathrm{M}=98.92, \mathrm{SD}=10.66)$ than the paedophilic child molesters $(\mathrm{M}=107.93, \mathrm{SD}=9.17 ; p=0.01)$. Furthermore, the non-paedophilic child molesters had spent more time in prison before testing $(\mathrm{M}=60.30, \mathrm{SD}=51.03)$ than the paedohilic child molesters $(\mathrm{Mean}=37.94, \mathrm{SD}=28.73 ; p=0.06)$. No significant differences were found between these groups with respect to age $(p=0.30)$ and overall psychopathy score $(p=0.49)$.

Table 3 about here

A significant main effect was found for phase $[F(1,45)=40.82, p<0.001]$ with higher error rates during reversal (Mean=6.54, $\mathrm{SE}=0.46)$ than acquisition $(\mathrm{Mean}=2.86, \mathrm{SE}=0.40)$, and contingency $[F(1,45)=35.45, p<0.001]$ with higher error rates for the 80-20 $($ Mean=6.43, $\mathrm{SE}=0.52)$ than the 100-0 contingency (Mean=2.97, $\mathrm{SE}=0.33)$. There was also a significant phasexcontingency interaction $[F(1,45)=18.92, p<0.001]$. There was also a significant main effect for subgroup $[F(1,45)=6.23, p=0.02]$. Pairwise comparison showed that nonpaedophilic child molesters made significantly more errors (Mean=5.50, $\mathrm{SE}=0.39)$ than their paedophilic counterparts (Mean=3.90, $\mathrm{SE}=0.51)$. No significant subgroup $\times$ phase $[F(1,45)=.37, p=.55]$ or subgroup $\times$ phase $\times$ contingency $[F(1,45)=1.30, p=0.26]$ interactions were found.

\section{Discussion}

This study was the first to demonstrate reinforcement learning impairments in child molesters, and to specify further the nature of the impairments. We found that child molesters, as a group, are impaired in their ability to acquire contingencies and to adapt when 
contingencies change. In the only prior study on this topic, Leue et al. (2008) found a reversal learning impairment in a mixed group of sex offenders. Our results fit with this finding, but also show that the reversal learning impairments are present among child molesters specifically, and that acquisition learning is also impaired among them. Finally, we confirmed that reinforcement learning impairments are more severe in non-paedophilic than in paedophilic child molesters.

One question left unanswered is the specificity of these impairments to child molesters. Performance of the offender controls fell between that of the child molesters and the non-offenders, suggesting that offender controls may have some difficulties with reinforcement learning, although, as a group, these general offender participants were not significantly different from the non-offenders. While this finding fits with Budhani et al., (2006), the lack of significant differences in our sample between child molesters and offender controls prevents us from concluding that these impairments are specific to child molesters.

When situating our findings in the reinforcement learning literature, we must bear in mind that reinforcement learning involves two key aspects. The first is that behaviour is guided by outcome expectancies that are represented in the orbitofrontal cortex (Rolls, 2000). These representations contain information about the characteristics and the value of the outcomes. Once formed, by associating outcomes to particular stimuli, they elicit expectations of reward/nonreward in response to these stimuli and prompt specific behaviour. The second aspect is that these representations are updated when outcome expectancies are violated because, for example, contingencies have changed. It is believed that it is the discrepancy between the expected and the actual outcome which leads to adjustments in the representations and drives adaptive behaviour (Schoenbaum, Roesch, Stalnaker, \& Takahashi, 2009). The reversal learning impairment seen in offenders with high psychopathy scores has been linked to this latter aspect and regarded as a problem in the updating of learned stimulus- 
outcome associations (Mitchell et al., 2002). In contrast, child molesters show a general reinforcement learning impairment that affects both acquisition and reversal learning. We propose that this impairment reflects an inability to form accurate representations of outcome expectancies (see Brazil, Mathys, Popma, Hoppenbrouwers, \& Cohn, 2017), which has been linked to the amygdala (Cador, Robbins, \& Everitt, 1989) and insula (Brazil et al., 2017). Such inability makes individuals less sensitive to estimating the reinforcing value of stimuli, which could (partly) explain the suboptimal learning and the subsequently poor choices found among child molesters. These hypotheses, including the proposed links with specific brain regions, should be further investigated in studies that combine neuropsychological and neuroimaging data.

An alternative interpretation is that the differences in reinforcement learning capabilities between child molesters and non-offenders relate to between-group differences in age. Child molesters were significantly older than non-offenders in this study and the correlation analysis showed a positive association between age and the number of errors made (see Appendix B). This latter finding concords with studies suggesting age-related declines in the acquisition and reversal of stimulus-reward contingencies (Eppinger, Hämmerer, \& Li, 2011). It is thus possible that age accounts for the reported impairments. Studies with matched designs are needed to draw firmer conclusions.

The reinforcement learning impairment found among child molesters has clinical implications, as it identifies an offender group who may struggle in therapy because of this. Offender therapy focusses on changing maladaptive behaviour and thinking patterns. This is typically done using behavioural modification techniques that incorporate the use of reinforcement to encourage appropriate behaviour, cognitive restructuring and new skill development. In this context, desired therapeutic effects may only be attained if, for those who have the impairments, offender therapy is enhanced by interventions to remedy the 
impairments (Baskin-Sommers, Curtin, \& Newman, 2015) and/or allow more time for learning.

\section{Conclusion}

Our study indicates the presence of reinforcement learning impairments, in both its acquisition and reversal learning components, among child molesters, especially those without paedophilic preferences. These impairments possibly reflect a more fundamental inability to form accurate stimulus-outcome associations. First remediying this impairment may help to improve treatment response among such men. 


\section{References}

American Psychiatric Association. (2000). Diagnostic and statistical manual of mental disorders: DSM-IV-TR. Washington, DC: Author. http://doi.org/10.1176/appi.books.9780890423349

Baskin-Sommers, A. R., Curtin, J. J., \& Newman, J. P. (2015). Altering the cognitiveaffective dysfunctions of psychopathic and externalizing offender subtypes with cognitive remediation. Clinical Psychological Science, 3(1), 45-57. http://doi.org/10.1177/2167702614560744

Behrens, T. E. J., Hunt, L. T., Woolrich, M. W., \& Rushworth, M. F. S. (2008). Associative learning of social value. Nature, 456, 245-249. http://doi.org/10.1038/nature07538

Brazil, I. A., Mathys, C. D., Popma, A., Hoppenbrouwers, S. S., \& Cohn, M. D. (2017). Representational uncertainty in the brain during threat conditioning and the link with psychopathic traits. Biological Psychiatry: Cognitive Neuroscience and Neuroimaging, 2(8), 689-695. http://doi.org/10.1016/j.bpsc.2017.04.005

Budhani, S., Richell, R. A., \& Blair, R. J. R. (2006). Impaired reversal but intact acquisition: probabilistic response reversal deficits in adult individuals with psychopathy. Journal of Abnormal Psychology, 115(3), 552-558. http://doi.org/10.1037/0021-843X.115.3.552

Cador, M., Robbins, T. W., \& Everitt, B. J. (1989). Involvement of the amygdala in stimulusreward associations: Interaction with the ventral striatum. Neuroscience, 30(1), 77-86. http://doi.org/10.1016/0306-4522(89)90354-0

Chen, C., Takahashi, T., Nakagawa, S., Inoue, T., \& Kusumi, I. (2015). Reinforcement learning in depression: A review of computational research. Neuroscience and Biobehavioral Reviews. http://doi.org/10.1016/j.neubiorev.2015.05.005

Cools, R., Clark, L., Owen, A. M., \& Robbins, T. W. (2002). Defining the neural mechanisms 
of probabilistic reversal learning using event-related functional magnetic resonance imaging. The Journal of Neuroscience, 22(11), 4563-4567. http://doi.org/20026435

Dargis, M., Wolf, R. C., \& Koenigs, M. (2017). Reversal learning deficits in criminal offenders: Effects of psychopathy, substance use, and childhood maltreatment history. Journal of Psychopathology and Behavioral Assessment, 39(2), 189-197. http://doi.org/10.1007/s10862-016-9574-6

De Brito, S. A., Viding, E., Kumari, V., Blackwood, N., \& Hodgins, S. (2013). Cool and hot executive function impairments in violent offenders with antisocial personality disorder with and without psychopathy. PloS One, 8(6). http://doi.org/10.1371/journal.pone.0065566

Eastvold, A., Suchy, Y., \& Strassberg, D. (2011). Executive function profiles of pedophilic and nonpedophilic child molesters. Journal of the International Neuropsychological Society, 17(2), 295-307. http://doi.org/10.1017/s1355617710001669

Eppinger, B., Hämmerer, D., \& Li, S.-C. (2011). Neuromodulation of reward-based learning and decision making in human aging. Annals of the New York Academy of Sciences, 1235(1), 1-17. http://doi.org/10.1111/j.1749-6632.2011.06230.x

Harris, A. J. R., \& Hanson, R. K. (2004). Sex offender recidivism : a simple question (User Report 2004-03). Ottawa: Public Safety Canada.

Joyal, C. C., Beaulieu-Plante, J., \& de Chantérac, A. (2014). The neuropsychology of sex offenders: A Meta-analysis. Sexual Abuse, 26(2), 149-177. http://doi.org/10.1177/1079063213482842

Kiehl, K. A., \& Hoffman, M. B. (2011). The criminal psychopath: history, neuroscience, treatment, and economics. Jurimetrics, 51, 355-397. http://doi.org/http://dx.doi.org/10.1108/17506200710779521

Leue, A., Brocke, B., \& Hoyer, J. (2008). Reinforcement sensitivity of sex offenders and non- 
offenders: an experimental and psychometric study of reinforcement sensitivity theory. British Journal of Psychology (London, England : 1953), 99(Pt 3), 361-78. http://doi.org/10.1348/000712607X228519

Mitchell, D. G. V., Colledge, E., Leonard, A., \& Blair, R. J. R. (2002). Risky decisions and response reversal: Is there evidence of orbitofrontal cortex dysfunction in psychopathic individuals? Neuropsychologia, 40(12), 2013-2022. http://doi.org/10.1016/S00283932(02)00056-8

Mitchell, D. G. V, Fine, C., Richell, R. A., Newman, C., Lumsden, J., Blair, K. S., \& Blair, R. J. R. (2006). Instrumental learning and relearning in individuals with psychopathy and in patients with lesions involving the amygdala or orbitofrontal cortex. Neuropsychology, 20, 280-289. http://doi.org/10.1037/0894-4105.20.3.280

Paulhus, D., Delroy, L., Neumann, C., \& Hare, R. (2016). Manual for the Self-Report Psychopathy Scale. Toronto: Multi-Health Systems.

Rolls, E. T. (2000). The orbitofrontal cortex and reward. Cerebral Cortex, 10(3), 284-294. http://doi.org/10.1093/cercor/10.3.284

Schmand, B., Bakker, D., Saan, R., \& Louman, J. (1991). The Dutch Reading Test for Adults: A measure of premorbid intelligence level. Tijdschrift Voor Gerontologie En Geriatrie, 22(1), 15-19. Retrieved from http://www.ncbi.nlm.nih.gov/pubmed/1877068

Schmidt, A. F., Gykiere, K., Vanhoeck, K., Mann, R. E., \& Banse, R. (2013). Direct and indirect measures of sexual maturity preferences differentiate subtypes of child sexual abusers. Sexual Abuse, 26(2), 107-128. http://doi.org/10.1177/1079063213480817

Schoenbaum, G., Roesch, M. R., Stalnaker, T. A., \& Takahashi, Y. K. (2009). A new perspective on the role of the orbitofrontal cortex in adaptive behaviour. Nature Reviews Neuroscience, 10(12), 885-892. http://doi.org/10.1038/nrn2753

Seto, M. C., \& Lalumière, M. L. (2001). A brief screening scale to identify pedophilic 
interests among child molesters. Sexual Abuse, 13, 15-25.

http://doi.org/10.1177/107906320101300103

Suchy, Y., Whittaker, J. W., Strassberg, D. S., \& Eastvold, A. (2009). Neurocognitive differences between pedophilic and nonpedophilic child molesters. Journal of the International Neuropsychological Society, 15(2), 248-257.

http://doi.org/10.1017/S1355617709090353

Van Groenestijn, M., Akkerhuis, G., Kupka, R., Schneider, N., \& Nolen, W. (1999). Gestructureerd klinisch interview voor de vaststelling van DSM-IV As-I stoornissen (SCID-I). Lisse: Swets \& Zeitlinger.

Vess, J., \& Skelton, A. (2010). Sexual and violent recidivism by offender type and actuarial risk: Reoffending rates for rapists, child molesters and mixed-victim offenders.

Psychology, Crime and Law, 16(7), 541-554.

http://doi.org/10.1080/10683160802612908

Waltz, J. A., \& Gold, J. M. (2007). Probabilistic reversal learning impairments in schizophrenia: Further evidence of orbitofrontal dysfunction. Schizophrenia Research, 93(1-3), 296-303. http://doi.org/10.1016/j.schres.2007.03.010

Weertman, A., Arntz, A., \& Kerkhofs, M. (2000). Gestructureerd diagnostisch interview voor DSM-IV As-II persoonlijkheidsstoornissen (SCID-II). Lisse: Swets Test Publisher. 
Table 1

Number of Participants who Failed to Reach the Learning Criterion

\begin{tabular}{cccc}
\hline \multicolumn{1}{c}{ Condition } & Child molesters & Comparison offenders & Non-offenders \\
\hline $\begin{array}{c}\text { Acquisition } \\
100-0\end{array}$ & 4 & 0 & 0 \\
$80-20$ & $(n=57)$ & $(n=32)$ & $(n=35)$ \\
& $7^{+}$ & 3 & $0^{+}$ \\
$(n=57)$ & $(n=32)$ & $(n=35)$ \\
Reversal & & & \\
$100-0$ & 2 & 0 & 0 \\
$80-20$ & $(n=53)$ & $(n=32)$ & $(n=35)$ \\
& 10 & 2 & 5 \\
& $(n=50)$ & $(n=29)$ & $(n=35)$ \\
\hline
\end{tabular}

Note. $100-0=100-0$ reinforcement contingency; $80-20=80-20$ reinforcement contingency.

${ }^{+}$Fisher's exact test (two-sided), $p=0.04$. 
Table 2

Demographic, Clinical and Sentence Characteristics of All Participants

\begin{tabular}{|c|c|c|c|c|c|c|c|c|c|c|c|c|}
\hline \multirow[b]{2}{*}{ Variable } & \multicolumn{3}{|c|}{ Child molesters } & \multicolumn{3}{|c|}{ Comparison Offenders } & \multicolumn{3}{|c|}{ Non-offenders } & \multicolumn{3}{|c|}{ Analyses } \\
\hline & $M$ & $S D$ & Range & $M$ & $S D$ & Range & $M$ & $S D$ & Range & Statistic & $p$ & Post hoc \\
\hline Age $(\text { years })^{\mathrm{a}}$ & 46.74 & 10.99 & $22-65$ & 36.90 & 10.12 & $20-58$ & 36.60 & 9.77 & $19-64$ & $12.58^{c}$ & $<0.001$ & $\begin{array}{l}\mathrm{CM}>\mathrm{Oc}^{* * *} \\
\mathrm{CM}>\mathrm{NO}^{* * *} \\
\mathrm{NO}=\mathrm{Oc}\end{array}$ \\
\hline $\mathrm{IQ}(\mathrm{NLV})^{\mathrm{b}}$ & 102.07 & 10.95 & $84-124$ & 97.03 & 8.97 & $81-114$ & 108.45 & 4.62 & $95-118$ & $21.36^{\mathrm{d}}$ & $<0.001$ & $\begin{array}{l}\mathrm{NO}>\mathrm{CM}^{* *} \\
\mathrm{NO}>\mathrm{Oc}^{* * *} \\
\mathrm{CM}=\mathrm{Oc}\end{array}$ \\
\hline SRP-SF Tot ${ }^{\mathrm{a}}$ & 62.04 & 13.21 & $39-102$ & 76.83 & 19.06 & $37-124$ & 48.54 & 14.24 & $31-76$ & $22.94^{\mathrm{d}}$ & $<0.001$ & $\begin{array}{l}\mathrm{CM}>\mathrm{NO}^{* * *} \\
\mathrm{Oc}>\mathrm{NO}^{* * *} \\
\mathrm{Oc}>\mathrm{CM}^{* *}\end{array}$ \\
\hline SRP-SF F $1^{\mathrm{a}}$ & 28.81 & 6.60 & $14-45$ & 32.69 & 8.94 & $18-54$ & 24.94 & 8.40 & $14-46$ & $7.76^{\mathrm{c}}$ & 0.00 & $\begin{array}{l}\mathrm{Oc}>\mathrm{NO}^{* * *} \\
\mathrm{CM}=\mathrm{NO}\end{array}$ \\
\hline
\end{tabular}




\begin{tabular}{|c|c|c|c|c|c|c|c|c|c|c|c|c|}
\hline \multirow[t]{3}{*}{ SRP-SF F2 ${ }^{a}$} & 33.23 & 8.35 & $19-57$ & 44.14 & 10.97 & $19-70$ & 23.60 & 6.91 & $15-39$ & $44.06^{c}$ & $<0.001$ & $\mathrm{CM}>\mathrm{NO}^{* * *}$ \\
\hline & & & & & & & & & & & & $\mathrm{Oc}>\mathrm{NO}^{* * *}$ \\
\hline & & & & & & & & & & & & $\mathrm{Oc}>\mathrm{CM}^{* * *}$ \\
\hline Incarc. & 52.21 & 45.24 & $6-186$ & 85.76 & 74.82 & $5-276$ & $\mathrm{n} / \mathrm{a}$ & $\mathrm{n} / \mathrm{a}$ & $\mathrm{n} / \mathrm{a}$ & $4.76^{d}$ & $0.04^{*}$ & $\mathrm{n} / \mathrm{a}$ \\
\hline
\end{tabular}

length

$(\text { months })^{\mathrm{a}}$

Note. $\mathrm{CM}=$ Child molesters; $\mathrm{Oc}=$ Comparison offenders; $\mathrm{NO}=$ Non-offenders $; \mathrm{NLV}=$ Dutch version of the National Adult Reading Test; SRP-SF Tot = Self-Report Psychopathy Short-Form Total psychopathy score; SRP-SF F1 = Self-Report Psychopathy Short-Form Interpersonalaffective; SRP-SF F2 = Self-Report Psychopathy Short-Form Impulsive-antisocial; Incarc. length = Time spent in prison until the moment of testing; $\mathrm{n} / \mathrm{a}=$ not applicable.

${ }^{\mathrm{a}} \mathrm{n}$ child molesters $=47, \mathrm{n}$ comparison offenders $=29, \mathrm{n}$ non-offenders $=35 .{ }^{\mathrm{b}} \mathrm{n}$ child molesters $=40, \mathrm{n}$ comparison offenders $=29, \mathrm{n}$ nonoffenders $=33$ ( 7 child molesters and 2 non-offenders did not complete the NLV due to Dutch not being their native language).

${ }^{\mathrm{c}} \mathrm{F}$ ANOVA, Bonferonni corrected post-hoc tests. ${ }^{\mathrm{d}}$ Welch ANOVA, Games-Howell post-hoc tests.

${ }^{*} p<0.05$. ${ }^{* *} p<0.01$. ${ }^{* * *} p<0.001$. 
Table 3

Demographic, Clinical and Sentence Characteristics of Paedophilic and Non-paedophilic

Child Molesters

Non-paedophilic child

\begin{tabular}{|c|c|c|c|c|c|c|c|c|}
\hline \multirow[b]{2}{*}{ Variable } & \multicolumn{3}{|c|}{ molesters } & \multicolumn{3}{|c|}{ Paedophilic child molesters } & \multicolumn{2}{|c|}{ Independent t-test } \\
\hline & $M$ & $S D$ & Range & $M$ & $S D$ & Range & $t$ & $p$ \\
\hline Age (years) ${ }^{\mathrm{a}}$ & 48 & 10.11 & $27-65$ & 44.53 & 12.40 & $22-62$ & 1.04 & 0.30 \\
\hline $\mathrm{IQ}(\mathrm{NLV})^{\mathrm{b}}$ & 98.92 & 10.66 & $84-124$ & 107.93 & 9.17 & $93-124$ & -2.67 & 0.01 \\
\hline SRP-SF Tot ${ }^{\mathrm{a}}$ & 61.03 & 11.39 & $45-94$ & 63.82 & 16.17 & $39-102$ & -0.69 & 0.49 \\
\hline SRP-SF F $1^{\mathrm{a}}$ & 28.63 & 6.34 & $14-44$ & 29.12 & 7.22 & $17-45$ & -0.24 & 0.81 \\
\hline SRP-SF F2 ${ }^{a}$ & 32.40 & 7.10 & $19-50$ & 34.71 & 10.28 & $21-57$ & $-0.82^{c}$ & 0.42 \\
\hline Incarc. & 60.30 & 51.03 & $6-186$ & 37.94 & 28.73 & $7-120$ & $1.92^{\mathrm{c}}$ & 0.06 \\
\hline length & & & & & & & & \\
\hline$(\text { months })^{\mathrm{a}}$ & & & & & & & & \\
\hline
\end{tabular}

Note. NLV = Dutch version of the National Adult Reading Test; SRP-SF Tot = Self-Report Psychopathy Short-Form Total psychopathy score; SRP-SF F1 = Self-Report Psychopathy Short-Form Interpersonal-affective; SRP-SF F2 = Self-Report Psychopathy Short-Form Impulsive-antisocial; Incarc. length $=$ Time spent in prison until the moment of testing. ${ }^{\mathrm{a}} \mathrm{n}$ non-paedophilic child molesters $=30, \mathrm{n}$ paedophilic child molesters $=17 .{ }^{\mathrm{b}} \mathrm{n}$ nonpaedophilic child molesters $=26, \mathrm{n}$ paedophilic child molesters $=14$ (4 non-paedophilic and 3 paedophilic child molesters did not complete the NLV due to Dutch not being their native language). ${ }^{\mathrm{c}}$ Levene's test for equality of variances, $p<0.05$. 
Figure 1. Mean number of errors in each phase for each contingency. The bars represent the mean number of errors committed prior to reaching the learning criterion per group in each phase for each contingency. Error bars represent standard error of the mean. Acq 100-0 = acquisition phase 100-0 contingency; Acq 80-20 = acquisition phase 80-20 contingency; Rev 100-0 = reversal phase 100-0 contingency; Rev 80-20 = reversal phase 80-20 contingency. No significant group differences were found for the phases and the contingencies separately. 


\section{Appendix A}

Measures

The Self-Report Psychopathy Short-Form (SRP-SF): The SRP-SF is a self-report measure that includes 29 items. It has 4 subscales: interpersonal manipulation, callous affect, erratic lifestyle, and criminal tendencies, which are combined to form 2 factor scores and an overall psychopathy score. Factor 1 (i.e., interpersonal-affective) comprises the interpersonal manipulation and callous affect subscales. Factor 2 (i.e., impulsive-antisocial) comprises the erratic lifestyle and criminal tendencies subscales.

The probabilistic reversal learning task: Six pairs of animals are presented throughout the task. Table A1 summarises the characteristics and the number of trials of each pair. Two of the six pairs (i.e., pair 2 and pair 4) are test pairs that are used to evaluate task performance. The remaining pairs are 'dummy' pairs that are presented alternately with the test pairs to increase task difficulty.

Table A1

Characteristics and Number of Trials of All Pairs of the Probabilistic Reversal Learning Task

\begin{tabular}{|c|c|c|c|}
\hline & \multirow[b]{2}{*}{ Characteristics } & \multicolumn{2}{|c|}{ Number of trials } \\
\hline & & Acq & Rev \\
\hline Pair 1 & Non-reversing pair with a $100-0$ contingency & 20 & - \\
\hline Pair 2 & Reversing pair with a $100-0$ contingency & 40 & 40 \\
\hline Pair 3 & Non-reversing pair with an 80-20 contingency & 40 & - \\
\hline Pair 4 & Reversing pair with an $80-20$ contingency & 40 & 40 \\
\hline Pair 5 & Non-reversing pair with a $100-0$ contingency & 40 & - \\
\hline Pair 6 & Non-reversing pair with a $100-0$ contingency & 10 & - \\
\hline
\end{tabular}

Note . Acq $=$ Number of acquisition trials; Rev $=$ Number of reversal trials; $-=$ No reversal trials for this pair. 


\section{Appendix B}

Additional Correlation Analyses

A Pearson correlation analysis for the entire sample showed a weak, but significant, positive link between age and the number of errors made in the 100-0 acquisition $(\mathrm{r}=.26, p=.01), 100-0$ reversal $(\mathrm{r}=.22, p=.02)$, and 80-20 reversal $(\mathrm{r}=.32, p=.00)$. In contrast, IQ, psychopathy scores, and incarceration length (only for child molesters and offender controls) did not correlate significantly with performance (Table B1).

A Pearson correlation analysis for the child molesters showed a significant positive association between age and the number of errors made, but only for the 80-20 reversal condition $(r=.35, p=.02)$. No significant correlations were found between the number of errors made and either IQ or psychopathy scores, or incarceration length (Table B2).

Table B1

Pearson Correlations for All Participants

\begin{tabular}{|c|c|c|c|c|}
\hline \multirow[b]{2}{*}{ Variable } & \multicolumn{2}{|c|}{ Acquisition } & \multicolumn{2}{|c|}{ Reversal } \\
\hline & $100-0$ & $80-20$ & $100-0$ & $80-20$ \\
\hline Age (years) ${ }^{\mathrm{a}}$ & $.26^{* *}$ & .13 & $.22^{*}$ & $.32^{* *}$ \\
\hline IQ (NLV) ${ }^{b}$ & -.16 & -.12 & -.17 & -.07 \\
\hline SRP-SF Tot ${ }^{\mathrm{a}}$ & -.03 & -.02 & .04 & -.02 \\
\hline SRP-SF F1 ${ }^{\mathrm{a}}$ & -.04 & -.02 & .06 & .01 \\
\hline $\begin{array}{l}\text { SRP-SF F2 }{ }^{\mathrm{a}} \\
\text { Incarc. length } \\
\text { (months) }^{\mathrm{c}}\end{array}$ & $\begin{array}{l}-.01 \\
.03\end{array}$ & $\begin{array}{l}-.02 \\
.09\end{array}$ & $\begin{array}{l}.02 \\
.01\end{array}$ & $\begin{array}{l}-.03 \\
-.06\end{array}$ \\
\hline
\end{tabular}

Note. $100-0=100-0$ reinforcement contingency; 80-20 $=80-20$ reinforcement contingency; NLV = Dutch version of the National Adult Reading Test; SRP-SF Tot $=$ Self-Report Psychopathy ShortForm Total psychopathy score; SRP-SF F1 = Self-Report Psychopathy Short-Form Interpersonalaffective; SRP-SF F2 = Self-Report Psychopathy Short-Form Impulsive-antisocial; Incarc. length = Time spent in prison until the moment of testing.

${ }^{\mathrm{a}} \mathrm{n}=111 .{ }^{\mathrm{b}} \mathrm{n}=102$ (7 child molesters and 2 non-offenders did not complete the NLV due to Dutch not being their native language). ${ }^{c} n=76$ (performed only for the child molesters and the offender controls). ${ }^{*} p<.05 .{ }^{* *} p<.01$. 
Table B2

Pearson Correlations for the Child Molesters

\begin{tabular}{|c|c|c|c|c|}
\hline \multirow[b]{2}{*}{ Variable } & \multicolumn{2}{|c|}{ Acquisition } & \multicolumn{2}{|c|}{ Reversal } \\
\hline & $100-0$ & $80-20$ & $100-0$ & $80-20$ \\
\hline Age $\left(\right.$ years) ${ }^{a}$ & .21 & .24 & .06 & $.35^{*}$ \\
\hline $\mathrm{IQ}(\mathrm{NLV})^{\mathrm{b}}$ & -.31 & -.09 & -.22 & .01 \\
\hline SRP-SF Tot ${ }^{\mathrm{a}}$ & -.08 & -.11 & .13 & -.06 \\
\hline SRP-SF F $1^{a}$ & .04 & -.07 & .17 & .04 \\
\hline 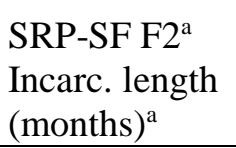 & $\begin{array}{l}-.15 \\
.20\end{array}$ & $\begin{array}{c}-.11 \\
.10\end{array}$ & $\begin{array}{c}.08 \\
-.11\end{array}$ & $\begin{array}{l}-.12 \\
-.03\end{array}$ \\
\hline \multicolumn{5}{|c|}{$\begin{array}{l}\text { Note. } 100-0=100-0 \text { reinforcement contingency; } 80-20=80-20 \text { reinforcement contingency; NLV = } \\
\text { Dutch version of the National Adult Reading Test; SRP-SF Tot = Self-Report Psychopathy Short- } \\
\text { Form Total psychopathy score; SRP-SF F1 = Self-Report Psychopathy Short-Form Interpersonal- } \\
\text { affective; SRP-SF F } 2=\text { Self-Report Psychopathy Short-Form Impulsive-antisocial; Incarc. length = } \\
\text { Time spent in prison until the moment of testing. } \\
{ }^{\mathrm{a}} \mathrm{n}=47 .^{\mathrm{b}} \mathrm{n}=40 \text { ( } 7 \text { child molesters did not complete the NLV due to Dutch not being their native } \\
\text { language). } \\
{ }^{*} p<.05 .\end{array}$} \\
\hline
\end{tabular}




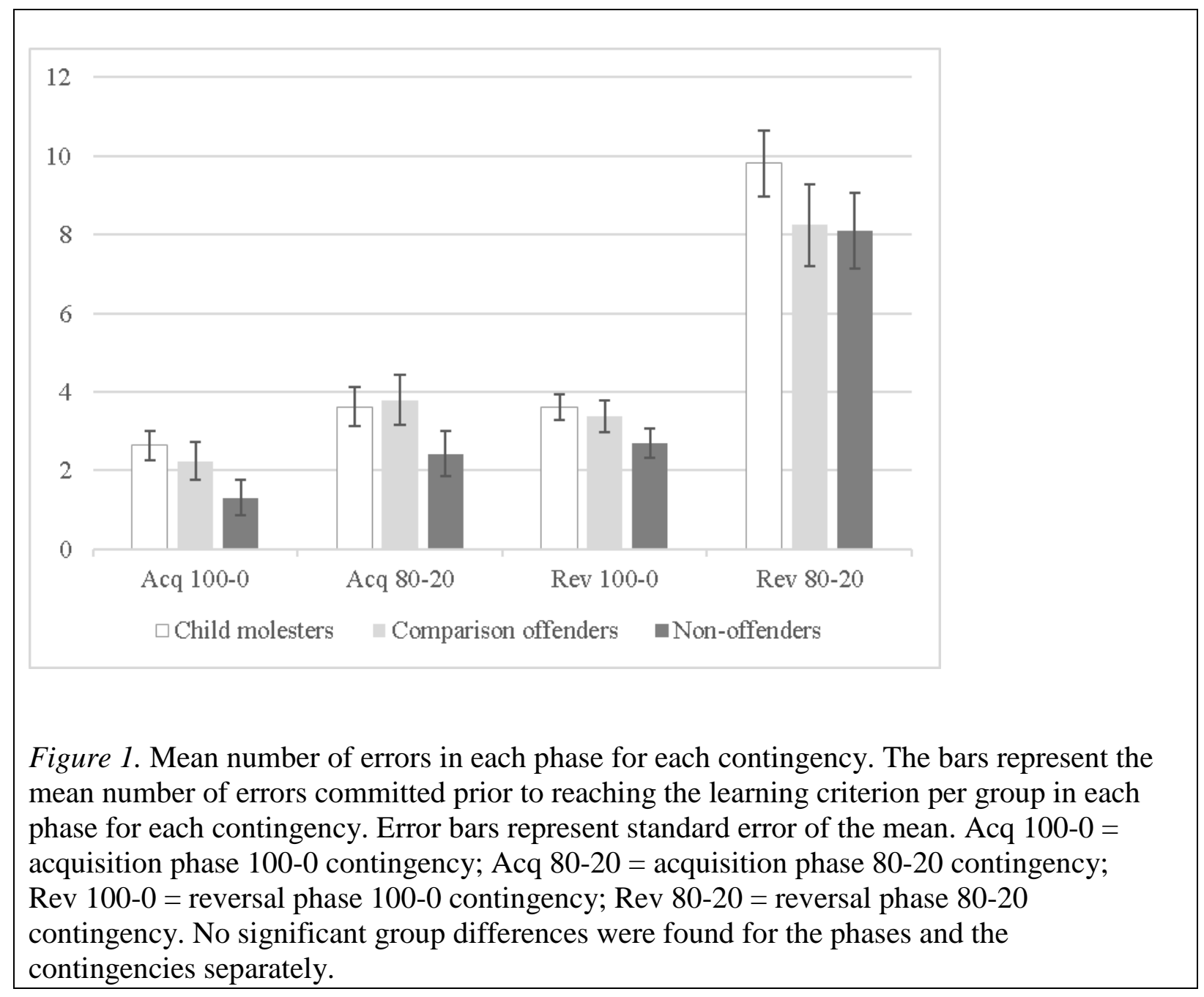

